\title{
Occupational Therapy and Product Design Students Learning Together
}

\author{
The Spectacle Story
}

MACHIKO NIIMI AND MARY BUTLER ${ }^{1}$

\begin{abstract}
This paper is a case study of a particular project (the Vision 20/20 project), which was developed by students on an interdisciplinary project. The goal of the project was to develop a child-to-child vision screening toolkit to integrate eye health into the school curriculum and make vision testing more accessible for children. An interdisciplinary research team was formed to support the students, and then continued to work together to ensure the ongoing sustainability of the project. The team used an action research approach and consisted of researchers and practitioners from three institutions: Otago Polytechnic, the University of Otago, and Tahuna Intermediate School (1013 year olds). It was made of occupational therapists, optometrists, product designers, teachers and learners (at multiple levels)This case study exemplifies how problembased learning can provide a context for students to do real work that makes a difference in the world. This goal of the Vision 20/20 project connects closely with the commitment underpinning the UN Sustainable Development Goals, which is to leave no one behind. The SDG for health (Goal 3: Good Health and Wellbeing) links with the World Health Organisation Global Action Plan on Universal Eye Health. There is considerable scope for this project to continue to develop in ways that will feed our long term goal of ensuring that no child is left behind because of poor vision. Similarly this project illustrates how faculty members from different disciplines can work together to develop a learning environment that enriches student's learning opportunities.
\end{abstract}

KEYWORDS: Interprofessional; Interdisciplinary; Project-based learning; Work-integrated learning; Heutagogy

1 Thanks to the passionate and creative students who contributed to the success of this project. These include. Aleisha McMurray and Tahlia Hapuku, final year occupational therapy students, who came up with the concept of child-to-child vision screening; Sarah Drummond, a final year occupational therapy student, who developed the teaching materials for the Vision 2020 project; and Curtis Stent, final year product design student who developed the flipchart. 


\section{Introduction}

This article reflects on the Vision 20/20 project which was led by an occupational therapy faculty member at Otago Polytechnic in Dunedin New Zealand. The project was developed as part of interprofessional project-based teaching practice and four students from different disciplines took part in it: three occupational therapy students and one product design student. The project was an example of how an interdisciplinary collaborative project can be developed from the ground up, when teachers are motivated to make this happen. A team of faculty members from health (occupational therapy and optometry) and design came together to supervise students and ensure longevity and sustainability of the project. The project also partnered with a local school (for 11 -3 year old), Tahuna Intermediate School to develop the project together.

This article will briefly explain the Vision 2020 project outcomes, then discuss how this project used various learning theories including work-integrated learning, heutagogical approaches and communities of practice to enrich student learning outcomes. Finally, our learnings from the collaborative learning environment will be discussed.

\section{Project description}

Core to the project was the goal of developing a vision testing kit that is accessible for children. The goal associates closely with the UN Sustainable Development Goal for health, (Goal 3: Good Health and Wellbeing). This links with the World Health Organisation Global Action Plan on Universal Eye Health, which calls for access to comprehensive and equitable eye care service for all with a particular emphasis on vulnerable group.

The Vision 2020 project developed as a response to limited opportunities for vision screening in New Zealand healthcare. The occupational therapy faculty member and students had identified that children could miss out on vision screening and consequently fail to get spectacles. Early detection and effective management of eye health conditions in children can reduce drop-out rates and improve academic excellence. Correcting vision using spectacles, can make a great difference to learning and general education which also contribute to the SDG on quality education (Goal 4) and reduces inequality (Goal 10).

In this project, students worked to develop materials that could be used as a part of Science, Technology, Engineering, Art and Maths (STEAM) curriculum. In the first instance, the concept of child-to-child vision testing was developed by two final year occupational therapy students. The students were able to draw on occupational therapy concepts of empowerment and person-centered practice to come up with the classroom scenario where children test each other. This was an innovative alternative to normal vision screening methods, and it highlights an ability to be observant and open minded on the part of the students. In addition, the occupational therapy faculty member, as a supervisor, needed to have trust in the capacity of the students in order to recognise the potential of this concept to make the vision screening more accessible for school children.

Eventually, following eighteen months of development, the final flipchart was based on 'tumbling Es', where children work in groups of threes to do the vision screening: one testing, one being tested and the other recording the results. The children take turns at testing each other, and the eventual results sheet is sent home to inform the parents and guardians whether the child needs to see a specialist for further eye exam. 
The second part of the project was the development of the Vision health and science teaching resource, put together by another final year occupational therapy student. The intention was to provide a complete package with the child-to-child vision screening as a practical exercise at the heart of the teaching, and the other teaching materials available as a wraparound teaching resource. The intention was to raise awareness of vision in the school community. Teachers would understand which children needed to go to an optometrist, and ideally children would also talk about the exercise at home. Obviously, a health promotion approach like this cannot ensure every child gets to an optometrist, but it did result in several children getting spectacles who would not otherwise have got them.

The next sections explain the learning theory underpinning this project and discusses how this way of teaching enriched this project.

\section{Learning theories underpinning the Vision 2020 project}

\section{Work-integrated learning}

In this project, students engaged in a project brief developed by a community group that aims to advocate for people with visual impairment across the lifespan (Vision Impairment Charitable Trust Aotearoa). The VICTA group works strategically with students in order to meet community needs, which meant that the students were working on a project that had a high level of priority. This is different to many situations, where students are often allocated to projects with low value to the community.

The kind of work-integrated learning exemplified by the Vision 2020 project can be called many different things. For example, it might fall under a course named:

- Practice placement

- Industry project

- Project Based Learning

- Internship

- Work-integrated learning

The important thing is to set up and supervise such educational experiences in a way that is sustainable. A checklist and rubric established by the Buck Institute (2019), gives a clear outline of the elements that are required to have a satisfactory project.

a) The opportunity to learn key skills in how to learn, including critical thinking, problem solving, collaboration and self-management

b) Base the project on a meaningful, open-ended and value-driven question

c) Use an active inquiry process of asking and answering questions

d) Situate the project in a real world context that makes a real impact

e) Enable real choices for the students about what they create, how they work and use their time

f) Provide opportunities for reflection on the design and implementation

g) Provide opportunities and time for students to give and receive feedback

h) Create a public product that is offered to people beyond the classroom.

Each of these elements was present for the students who worked on the child-to-child vision screening project. 


\section{Heutagogical theory of learning}

There are several theories of learning that underpin the kind of work-integrated learning that this is described in this paper, including experiential and reflective learning (Kolb, 1984) and workplace learning theory (Billett, 2002, 2006, 2012, 2016). One educational philosophy that is relevant to this kind of project-based learning is 'heutagogy' (Hase \& Kenyon, 2007).

Educators in vocational degrees have found heutagogy to be a realistic response to the issues faced by learners in a workplace that is constantly changing. It is an approach that makes sense of the many uncertainties that accompany the outcomes of a project like the one described here. This is a student-centred approach that moves beyond both pedagogy and androgogy to one where the teacher provides resources but the learner designs the actual course he or she might take by negotiating the learning. The ideal is one where assessment becomes more of a learning experience than a means to measure attainment. A key concept in heutagogy is that of double-loop learning, where learners consider the problem and the resulting action and outcomes, and then integrate this understanding into a reflection on how it influences the learner's own beliefs and actions (see Figure 1).

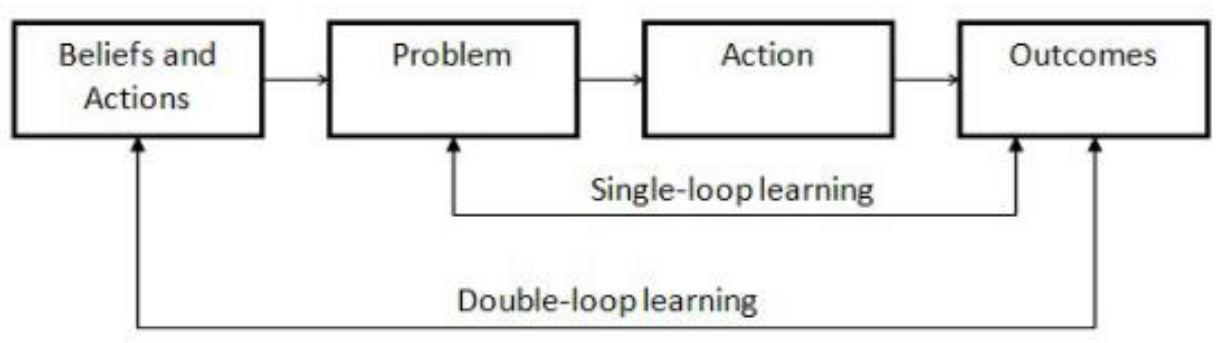

Figure 1 - Double-loop learning (Eberle \& Childress, 2009, cited in Blaschke, L. M.,2012)

In this project, reflective learning was demonstrated in the discovery of a core value underpinning the work of the students and those guiding their learning. This was articulated as "leave no child behind when it comes to vision". Double-loop learning was also exhibited throughout the project as students went through a deeply self-reflective process with each round of feedback.

In this project the learning process of the students was parallelled by an action research process, where their work was eventually built into a credible academic output. Action research is another form of reflective practice, which gives learners and researchers an opportunity to experiment with real-world scenarios, and this way also prepares them for the professional workplace (Hase \& Kenyon, 2007, p. 113).

\section{Interprofessional and interdisciplinary learning}

The American Occupational Therapy Association's Vision 2025, suggests that interprofessional partnerships between occupational therapy and designers is necessary to "maximize health, well-being, and quality of life for all people ... through effective solutions that facilitate participation in everyday living" (2016, para 1). Unfortunately, it is very common for occupational therapists and designers to lack understanding of each other's fields and there often little opportunity to break these barriers down during student training (Wagenfeld, Reynolds \& Amiri, 
2017). This fact increases the importance of the project described, since it provides an excellent example of such a partnership.

Such collaborations can be challenging, especially in situations where language about what this collaboration means is contested. For example, 'interprofessional' is often the preferred term for collaboration used by health professionals. The term interprofessional collaboration situated in health is described as "when multiple health workers from different professional backgrounds work together with patients, families, carers, and communities to deliver the highest quality of care." (WHO, 2010 p7). In the health environment interprofessional collaboration is linked to better outcomes for families and patients (WHO 2010). It is unusual, however, to have interprofessional collaboration extend beyond the boundaries of healthcare practice. This project was an excellent example of the efficacy of bringing together health professionals (occupational therapy and optometry) with product designers. Interprofessional practice aims at practice that can be collaborative and integrated (D'Amour and Onadasan, 2005) but does not aim to break boundaries between professional practices.

Interdisciplinary practice, on the other hand, can be more about creating completely new kinds of knowledge. In the field of design, people from different professional backgrounds working together is often described as an Interdisciplinary collaboration. Common collaborations are between designers and engineers, architects and structural engineers and there are many ways of working that may be seen as collaboration (Klaasen 2018). The benefit of collaboration is that it can increase the capacity to address complex problems with a broad pool of knowledge (Bart, et al, 2015). Klein and Newell (1998) give the often-quoted definition of interdisciplinary studies:

"A process of answering a question, solving a problem, or addressing a topic that is too broad or complex to be dealt with adequately by a single discipline or profession. It draws on disciplinary perspectives and integrates their insights through construction of a more comprehensive perspective" (pp.3).

In the case of this project, students were engaged in a process that was both interdisciplinary and interprofessional practice.

Similarly, this project saw the students engage in a community of practice. In a qualitative study, Sterrett (2010) described the key factors of an interprofessional community of practice. These clustered around the themes of mutual engagement, joint enterprise and an essential atmosphere of respect.

In terms of mutual engagement, students and the team spoke often about the collective value of improving the quality of life for children with visual impairments in schools. A very important part of the project, as mentioned above, was the way that the team was able to find common ground in value that was expressed about 'leaving no child behind'. This was a fundamental element of the project, because it meant that students did not work at cross purposes. The students were part of a team, which was able to negotiate the tensions because of the commitment to common values (Niimi, et al 2020). The iterative process meant that there was a need to adopt and let go of ideas relatively quickly. These were articulated in a weekly meeting and changes were rapidly synthesised. The value-based nature of the project (i.e. leave no child behind), enabled the development of a creative and neutral space (Klaasen, 2018). One obvious outcome was that this democratic approach opened up a space that offered students the opportunity to develop leadership and interpersonal skills. This is what the product design student said

"It's been great doing human-centred work and [to] get feedback from people as you go. It means I can make the best product possible. It's been very rewarding." 
There was also a sense of common enterprise. It was clear that the project needed the boundaries between the professions of product design and occupational therapy. The fact that each discipline brought a diverse perspective was very important. The essential premise of co-design argues that a design of a products or services, should involve both designers as well as non designers and experts from related fields in an equal creative partnership. Rapid progress can be made when specialist knowledge and end user knowledge (in this case, optometrist, teachers and children) can validate design decision-making process (Saunders, 2008).

The students were in their final year of study, which meant that they had a degree of competence in their respective disciplines that was important to bring to the project. Because the project occurred in tertiary education, there was a process where the proposal was initially floated widely and the students personally opted in to the project from their respective disciplines. Although the pair had never met or worked with each other before, nor did they have a real appreciation of each other's discipline, they worked in a close partnership to make concept development and testing happen, fast. The product design student completed designing the print materials for vision screening before graduating. The occupational therapy student wanted to take some time from her studies. She was offered and took on a fixed term project management role for the project in the following year, where she made a significant contribution to developing the content which is now available online.

There was an essential respect within the whole community of practice. Everyone was needed including the children in the primary school. Indeed, in one of the final stages of the project, the baton was passed to a team of children aged 11-13 who had worked closely with the above occupational therapy and product design students. They had been involved in testing their concepts and providing feedback multiple times. This team of children worked together to film a short video on how to use the vision screening kit in a classroom environment. The video is now a vital piece of the teaching resource made available on the online Science Learning Hub where teachers and children from around the world can access the Vision 20/20 tools.

\section{Conclusion}

This paper describes a successful collaboration between occupational therapy and product design students. It was successful both in terms of the kind of heutagogical learning that was made available to students, who clearly thrived and rose to the challenge over the course of many months. It was also successful in terms of the interdisciplinary practice that arose from the collaborative relationships formed between the whole team. Ultimately, the drive and commitment of the students ensured that the original kernel of an idea was eventually translated into practice.

The excellent outcome from this set of student projects is the result of a rather complex set of circumstances. Key elements included the continuity that was enabled through the process of 'passing on the baton'. The project was intensely value-based, and this was an essential glue that held both the team and the project in place. It enabled the team to find a capacity for dialogue that went beyond discipline specific language and ways of doing. The concept of child-to-child vision screening was significantly novel, but the shared value meant that a potentially radical idea was smuggled across the boundaries of between health and education.

The project exemplifies how students can work in an interdisciplinary team to make a real difference in the world. Students were able to practice with autonomy, while still receiving 
guidance; they could use critical thinking and decision making skills as equals in a team of professionals because of their commitment to the project.

From a supervision perspective, academics are often encouraged by institutional agenda to supervise interdisciplinary projects with real-world outcomes with community impact. This project is a case study that highlights the amount of effort and time required to sustain an industry project to the point where it can receive external funding and achieve a real-world impact.

\section{Literature}

American Occupational Therapy Association. (2016). AOTA unveils Vision 2025. Retrieved from http://www.aota.org/aboutaota/vision-2025.aspx

Bart, N., Green, DC., Claire, D. Johnson, DC. (2015) Interprofessional collaboration in research, education, and clinical practice: working together for a better future. Journal of Chiropractic Education 29 (1), p1-10.

Billett, S. (2002) Critiquing Workplace Learning Discourses: Participation andContinuity At Work, Studies in The Education Of Adults 34(1) 56-67

Billett, S. (2006) Constituting the Workplace Curriculum, Journal Of Curriculum Studies, 38(1), 31-48

Billett, S. (2016). Learning through health care work: Premises, contributions and practices. Medical Education, 50(1), 124-131. https://doi.org/10.1111/medu.12848

Blaschke, L. M. (2012). Heutagogy and lifelong learning: A review of heutagogical practice and self-determined learning. International Review of Research in Open and Distance Learning, 13(1), 56-71. https://doi.org/10.19173/irrodl.v13i1.1076

Buck Institute for Education, 2019. Essential Project Design Elements Checklist.

Retrieved from https://my.pblworks.org/system/files/documents/PBLworks-Essential-Project-Design-Elements.pdf

D'amour, D. \& Oaandasan, I. (2005) Interprofessionality as the field of interprofessional practice and interprofessional education: An emerging concept, Journal of interprofessional care, $1,8-20$

Hase, S. \& Kenyon, C. (2007). Heutagogy: A child of complexity theory. Complicity: An International Journal of Complexity and Education, 4(1), 111-119.

Kenyon, C., \& Hase, S. (2001). Moving from andragogy to heutagogy in vocational education Hase-Kenyon_full.pdf. Retrieved from

https://citeseerx.ist.psu.edu/viewdoc/download?doi=10.1.1.527.3327\&rep=rep1\&type=pdf

Klaassen, R.G. (2018) Interdisciplinary education: a case study. European Journal of Engineering Education, 43 (6) 842-859

Klein, J. \& Newell, W. (1998). Advancing Interdisciplinary Studies. In W. Newell (Ed.), Interdisciplinarity: Essays from the literature (pp. 3-22). New York: College Board.

Kolb, D. A. (1984). Experiential learning: Experience as the source of learning and development (Vol. 1). Englewood Cliffs, NJ: Prentice-Hall.

Lave, J. \& Wenger, E.(1991) Situated learning: Legitimate peripheral participation, Cambridge University Press.

Niimi, M., Butler, M., Drummond, S., Ogbuehi, K., \& Parker, K. (2020) Designing Together: "Vision 2020: Co-design Project", Scope Health \& Wellbeing 5, 79 - 84.

Rogers C R (1951) Client centred therapy. Boston: Houghton Mifflin. 
Saunders, E. B-N., \& Stapparsb, P. J. (2008). Co-creation and the new landscapes of design. CoDesign, 4(1), 5-18.

Sterrett, S. E. (2010). Becoming an Interprofessional Community of Practice: A Qualitative Study of an Interprofessional Fellowship. Journal of Research in Interprofessional Practice and Education, 1(3). https://doi.org/10.22230/jripe.2010v1n3a33

Sustainable Design Council (2019) The Future of Work thinkpiece - February 2019. Full pdf.

Retrieved from

https://www.sbc.org.nz/_data/assets/pdf_file/0009/162495/14022019-FoW-Boardroomthink-piece.pdf.

Wagenfeld, A., Reynolds, L., \& Amiri, T. (2017). Exploring the Value of Interprofessional Collaboration between Occupational Therapy and Design: A Pilot Survey Study. The Open Journal of Occupational Therapy, 5(3). https://doi.org/10.15453/2168-6408.1354

World Health Organisation (2010) Framework for Action on Interprofessional Education \& Collaborative Practice, Health Professions Networks Nursing \& Midwifery Human Resources for Health. Retrieved 2/5/21 from https://apps.who.int/iris/bitstream/handle/10665/70185/WHO_HRH_HPN_10.3_eng.pdf;jses,

World Health Organisation (2019) World report on vision, Retrieved 2/5/21 from https://www.who.int/publications/i/item/9789241516570 